\title{
PERANCANGAN SISTEM INFORMASI MANAJEMEN AKTIVITAS WORKSHOP DI PT. SIGNIFY COMMERCIAL INDONESIA
}

\author{
Imam Shafi' ${ }^{1}{ }^{1}$, Rahmawati $^{2}$ \\ 1,2Informatika, Fakultas Teknik dan Ilmu Komputer, Universitas Indraprasta PGRI \\ Jalan Raya Tengah No 80, Kelurahan Gedong, Pasar Rebo, Jakarta Timur \\ 1.imamshafii2201@gmail.com, 2 rhmarisma10@gmail.com
}

\begin{abstract}
ABSTRAK
Sistem informasi dan teknologi komputer saat ini berkembang sangat cepat karena teknologi dapat membuat pekerjaan menjadi lebih bertepat guna terutama untuk pendataan. Pendataan aktivitas disebuah workshop membutuhkan manajemen yang baik seperti yang dibutuhkan oleh PT. Signify Commercial Indonesia. Pengolahan data aktivitas di workshop masih menggunakan cara menuliskan manual yang menyebabkan lambatnya pengolahan data yang tidak terstruktur dengan baik. Hal tesebut mempengaruhi kecepatan pekerjaan yang dilakukan sehingga pelanggan tidak merasa senang karena menunggu terlalu lama. Permasalahan kelambatan dan akurasi data dapat diatasi dengan melakukan perancangan sistem informasi pengelolaan data aktivitas workshop menggunakan pemrograman java dan penyimpanan data MySql. Perangkat lunak dibuat bertujuan untuk memudahkan proses sistem pendataan menjadi terkomputerisasi. Metode penelitian yang digunakan yaitu metode grounded (grounded research) dan metode pengembangan sistem waterfall. Hasil dari penelitian adalah untuk mempermudah proses pendataan. Sistem yang ada pada aplikasi aktivitas workshop menjadi data terkomputerisasi, rapih dalam hal penyimpanan data, laporan menjadi efektif dan pelanggan menjadi senang dengan pelayanan yang diberikan.
\end{abstract}

Kata Kunci: Sistem Informasi, Aktivitas Workshop, MySQL

\begin{abstract}
The rapid development of computer and information technology nowadays has tremendously impacted work efficiency improvement including data collection. Data collection regarding activities in a workshop has to be managed properly as required by PT. Signify Commercial Indonesia. Currently, the data collection activity in workshop still uses write manual methods which cause slow and unstructured data processing. Therefore, the working pace is slower than expected and causes dissatisfied customers after waiting too long. In order to overcome those problems, the data management system regarding activities in workshop was designed using Java programming and MySql database. This software development aims to facilitate data collection process systems easier and more computerized. This research uses qualitative method grounded (grounded research) data with waterfall system methodology. The results show that the data collection process is easier than expected. It also proves that the system in workshop activity application is computerized, well-organized data storage, more effective report, and finally improve the customer's satisfaction of our service.
\end{abstract}

Key Word: Information Systems, Workshop Activity, MySQL

\section{PENDAHULUAN}

Sistem informasi dan teknologi komputer berkembang sangat cepat belakangan ini karena teknologi membantu pekerjaan menjadi lebih bertepat guna terutama untuk pendataan. Saat ini masih banyak aktivitas di perusaahn menggunakan catatan manual yang menyebabkan terjadinya penumpukan dokumen atau kertas yang jika aktifitas perusahaan tinggi maka akan sangat mengganggu dan mempengaruhi kecepatan pekerjaan. Menurut Zeithaml, Bitner, dan Gremler (Zeithaml, V.A., Bitner, M.J., Gremler, 2009) berpendapat bahwa "kepuasan konsumen dipengaruhi oleh kualitas layanan yang diberikan oleh sebuah perusahaan" salah satunya adalah keandalan atau kecepatan dalam melayani pelanggan. Kepuasan pelanggan menurut Shandy (Widjoyo, 2014) "Apabila kinerja yang diterima lebih rendah dari yang diharapkan, maka konsumen akan merasa tidak puas. Sebaliknya, apabila kinerja yang diterima sesuai dengan yang diharapkan, maka konsumen akan merasa puas. Konsumen akan merasa sangatpuas apabila kinerja yang diterima melebihi harapannya."

Aktivitas pengolahan data di workshop PT. Signify Commercial Indonesia masih menggunakan cara menulis dokumen secara manual yang menyebabkan lambatnya 
pengolahan data yang tidak terstruktur dengan baik. Hal tesebut mempengaruhi kecepatan pekerjaan yang dilakukan sehingga pelanggan tidak merasa puas karena menunggu terlalu lama.

Hal serupa terjadi juga di Bengkel Gama Auto Service. Pada jurnal Deni Rohnadi (Deni Rohnadi, 2019) "Perancangan Sistem Informasi Menejemen Bengkel Di Gama Auto Service" dijelaskan bahwa permasalahan yang terjadi adalah karena administrasi yang masih dikerjakan secara manual sehingga menyebabkan terlambatnya proses pelayanan dan mengakibatkan pelanggan tidak merasa puas.

Advan Service Center Jambi juga terjadi permasalahan yang sama dimana proses pengolahan keluar dan masuknya data barang masih dilakukan dengan pencatatan di buku yang terkadang lupa dicatat oleh admin, sehingga terjadi kesalahan mengenai informasi barang yang mengakibatkan terjadinya pemesanan barang ulang ke supplier dan memerlukan waktu yang lama untuk menunggu barang tersebut datang sehingga pelanggan harus menunggu lama untuk pesanannya. Hal tersebut dijelaskan dalam jurnal Amelia dan Devitra (Amelia \& Devitra, 2018) "Analisis dan Perancangan Sistem Informasi Manajemen Persediaan Barang pada Advan Service Center Jambi”.

Dari paparan problematika di atas maka peneliti merancang suatu system informasi manajemen aktivitas workshop di PT.Signify Commercial Indonesia yang berfungsi untuk mengolah data agar lebih mempermudah pekerjaan sekaligus memberikan kepuasan terhadap pelanggan.

Aplikasi aktivitas workshop memungkinkan pengguna mengatur dan mendata penerimaan complaint, penerimaan stock, pengeluaran complaint, penjualan komponen, peminjaman alat atau komponen dan pengiriman sample. Tujuan dari sistem informasi ini adalah data menjadi terkomputerisasi, rapih dalam hal penyimpanan data, laporan menjadi efektif dan pelanggan menjadi senang dengan pelayanan yang diberikan.

\section{METODE PENELITIAN}

Menurut Hidayat (Hidayat, 2017) metode penelitian adalah langkah yang dimiliki dan dilakukan oleh peneliti dalam rangka untuk mengumpulkan informasi atau data serta melakukan investigasi pada data yang telah didapatkan tersebut. Menurut Saifuddin (Saifuddin, 2010) Metode penelitian adalah sebagai cara ilmiah untuk mendapatkan data dengan tujuan dan kegunaan tertentu

Dari sumber diatas maka Metode penelitian yang digunakan penulis adalah dengan mengumpulkan berbagai informasi berupa data untuk pemecahan masalah dan menemukan jawaban dari masalah yang terjadi di Workshop PT. Signify Commercial Indonesia. Peneliti menggunakan metode grounded (grounded research) yaitu suatu metode penelitian berdasarkan pada fakta dan menggunakan analisis perbandingan dengan tujuan mengadakan generalisasi empiris, menetapkan konsep, membuktikan teori, mengembangkan teori, pengumpulan dan analisis data dalam waktu yang bersamaan (Dwi Pratiwi, 2020). Model ini mengusulkan sebuah pendekatan perangkat lunak yang sistematik dan sekuensial yang dimulai pada tingkat dan kemajuan sistem pada seluruh analisis, desain, kode, pengujian dan pemeliharaan (Ysh, 2012).

Langkah-langkah yang dilakukan yaitu dengan menentukan permasalahan yang sering terjadi di aktivitas workshop PT. Signify Commercial Indonesia. Selanjutnya adalah pengumpulan data dengan cara wawancara atau observasi yang berfungsi untuk analisa terhadap proses perancangan sistem informasi di workshop PT. Signify Commercial Indonesia. Setelah diketahui permasalahan yang terjadi maka dilakukan analisa kebutuhan sistem bersama user agar permasalahan dan aplikasi yang akan dibuat menjadi lebih efktif dan pekerjaan berjalan dengan cepat dan lancar.

\section{HASIL DAN PEMBAHASAN}

Berdasarkan hasil penelitian yang telah dilakukan yaitu dengan mengumpulkan permasalahan yang terjadi, wawancara dan observasi untuk menganalisa permasalahan yang terjadi di Workshop PT. Signify Commercial Indonesia maka didapatkanlah hasil sebagai berikut : 


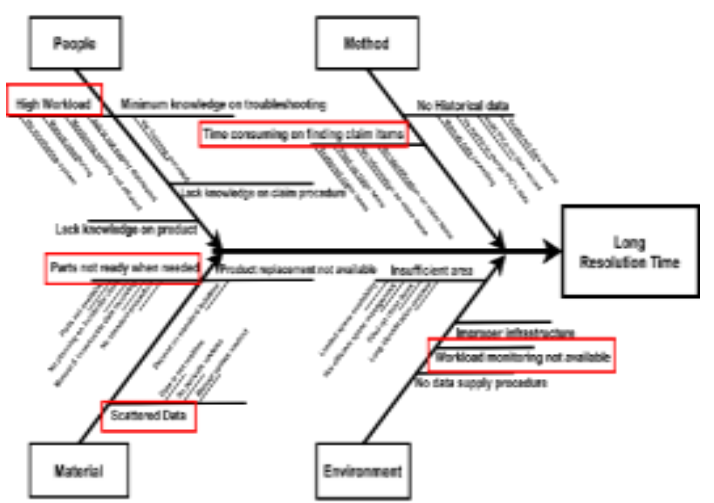

Gambar 1. Root Cause Analysis (Fishbone)

Proses pendataan masih dilakukan secara manual yang menyebabkan seringnya terjadi kesalahan data dan membuat proses terlalu lama. Proses komplain dari datangnya barang hingga selesai membutuhkan waktu rata-rata 44 hari kerja. Selain dari proses komplain,, pendataan secara manual membuat stok barang di workshop menjadi berantakan dan menyebabkan beberapa komponen tidak tersedia. Hal tersebut membuat pelanggan menjadi tidak senang dengan pelayanan yang diberikan.

Dari permasalahan tersebut maka diusulkan sistem sebagai berikut :

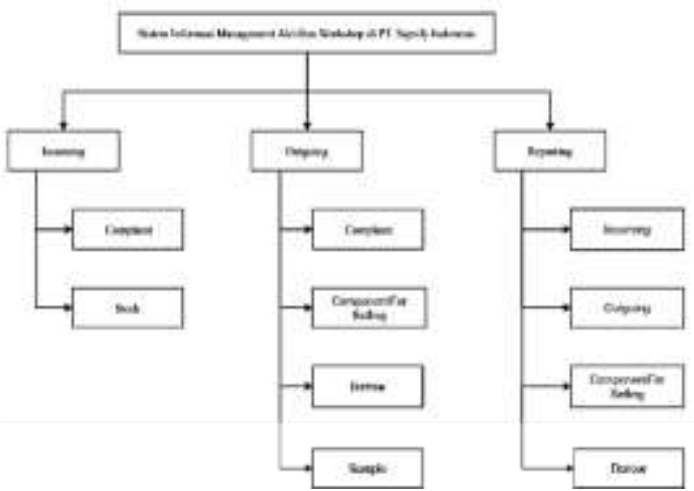

Gambar 2. Dekomposisi Sistem Diusulkan

Melihat masalah yang ada, peneliti merancang sebuah sistem informasi manajemen aktifitas di workshop PT.Signify Commercial Indonesia. Sistem informasi ini dapat mendata setiap aktifitas di workshop baik kedatangan barang, pengeluaran barang dan reporting untuk barang komplain maupun barang stok. Sistem tersebut memerlukan hubungan antar data atau Entity Relationship Diagram (ERD). Menurut (Ibeng, 2018) "Entity Relationship Diagram (ERD) adalah suatu model untuk menjelaskan mengenai hubungan antar data dalam basis data berdasarkan objek-objek."
Menurut Mulyani (Mulyani, 2014) ERD (Entity Relationship Diagram) merupakan tools yang digunakan untuk memodelkan struktur data dengan menggambarkan entitas dan hubungan antara entitas (relationship) secara abstrak (konseptual).

ERD (Entity Relationship Diagram) adalah suatu model untuk menjelaskan hubungan antar data dalam basis data berdasarkan objekobjek dasar data yang mempunyai hubungan antar relasi. Perancangan sistem informasi manajemen aktivitas di workshop PT.Signify Commercial Indonesia berbasis java menggunakan database MySql.

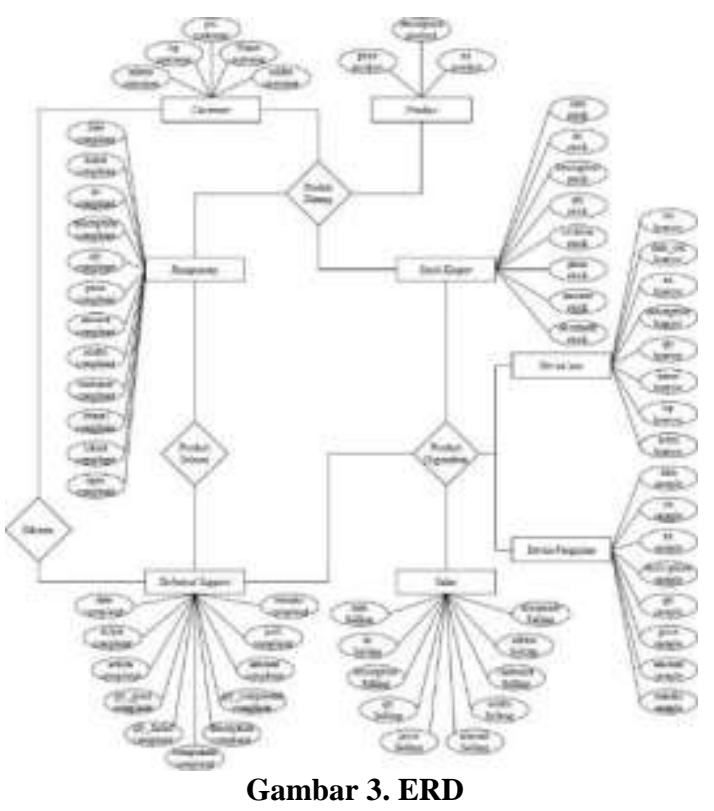

Berikut adalah tampilan dari sistem informasi manajemen aktivitas workshop di PT. Signify Commercial Indonesia :

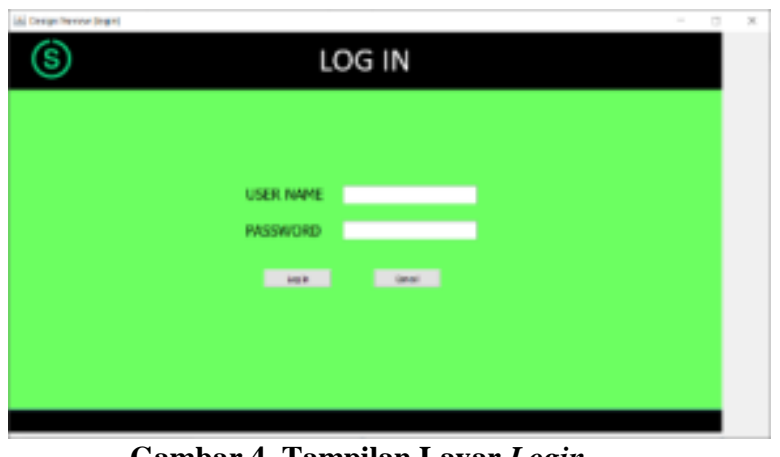

Gambar 4. Tampilan Layar Login

Pada tampilan Menu login user dapat memasukan user dan password yang telah dibuat, lalu dapat memilih button "Login". 
Layar ini berfungsi untuk mengamankan sistem jadi hanya pengguna yang berkepentingan saja yang bisa mengakses sitem ini

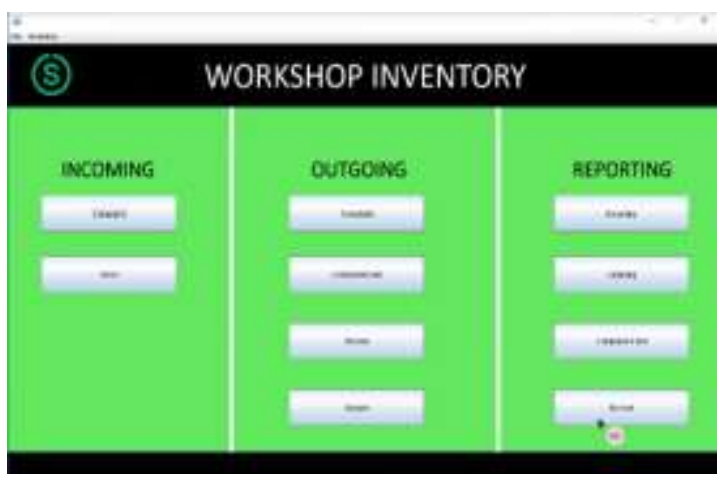

Gambar 5. Tampilan Layar Menu Utama

Di Layar utama banyak tombol menu yang siap di gunakan oleh user sesuai dengan fungsinya masing-masing. Layar ini berfungsi untuk memilih menu yang akan digunakan.

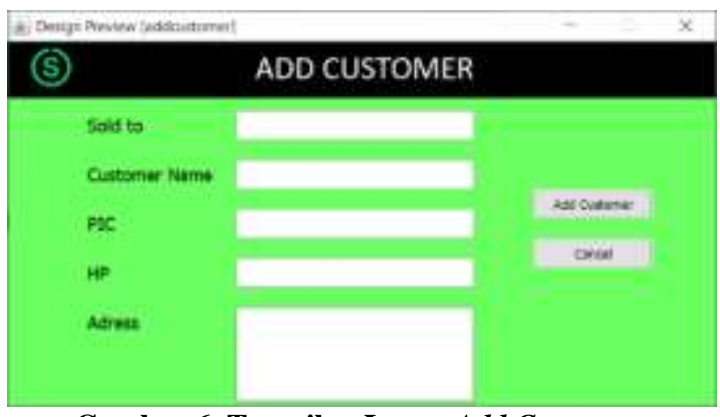

Gambar 6. Tampilan Layar Add Customer

Pada menu add customer, user dapat menambahkan data informasi customer. Layar ini berfungsi untuk menambahkan informasi mengenai customer kedalam database sehingga mempermudah user ketika memasukkan data customer.

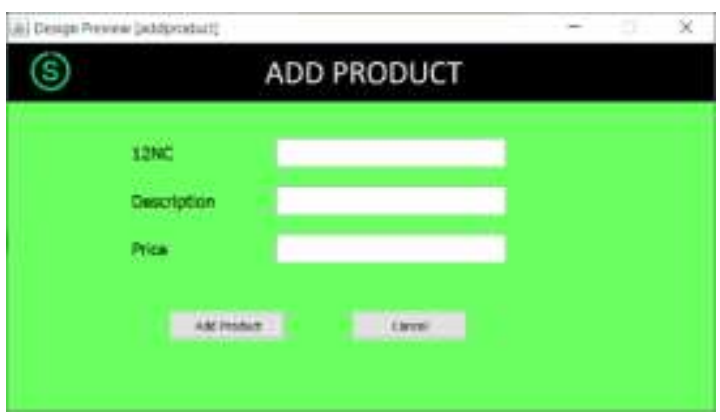

Gambar 7. Tampilan Layar Add Product

Pada menu add product, user dapat menambahkan data informasi product. Layar ini berfungsi untuk menambahkan informasi mengenai product kedalam database sehingga mempermudah user ketika memasukkan data product.

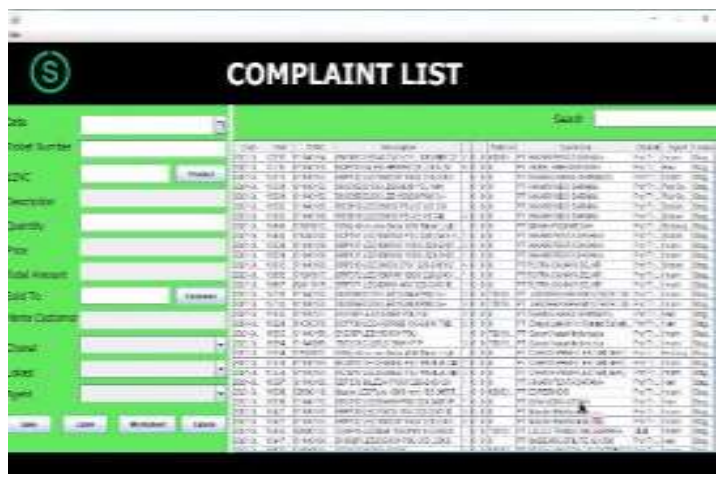

Gambar 8. Tampilan Layar Incoming Complaint

Pada menu incoming complaint, user dapat menambahkan, menghapus, mengubah, dan mencari data complaint. Layar ini berfungsi untuk melihat dan menginformasikan mengenai kedatangan barang complaint dari customer.

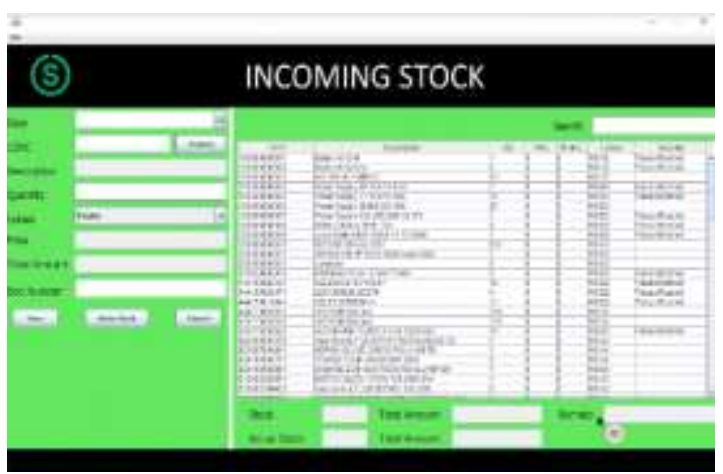

Gambar 9. Tampilan Layar Incoming Stock

Pada menu incoming stock, user dapat menambahkan, menghapus, mengubah, mencari, dan mereset data stock. Layar ini berfungsi untuk melihat dan menginformasikan mengenai kedatangan stok barang.

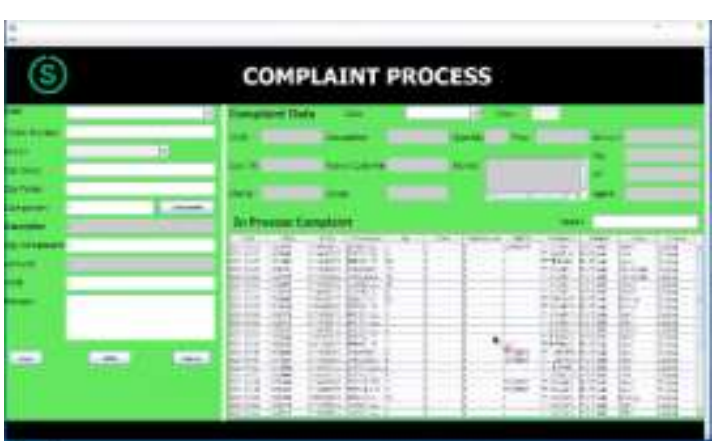

Gambar 10. Tampilan Layar Outgoing Complaint

Pada menu outgoing complaint, user dapat menambahkan, menghapus, mengubah, dan 
mencari data. Layar ini berfungsi untuk melihat dan menginformasikan mengenai barang complaint dari customer yang sudah selesai dikerjakan dan dikembalikan ke customer.

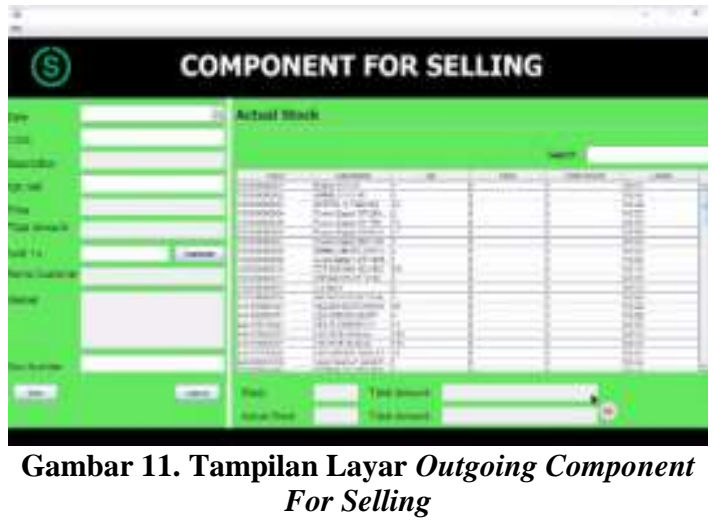

Pada menu component for selling, user dapat menambahkan, menghapus, mengubah, dan mencari data komponen untuk dijual. Layar ini berfungsi untuk melihat dan menginformasikan mengenai stok barang keluar untuk dijual.

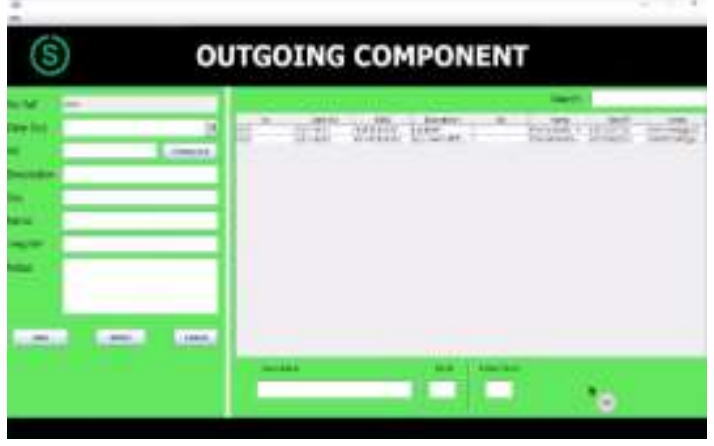

Gambar 12. Tampilan Layar Outgoing Borrow

Pada menu borrow, user dapat menambahkan, menghapus, mengubah, dan mencari data. Layar ini berfungsi untuk melihat dan menginformasikan mengenai barang keluar yang dipinjamkan.

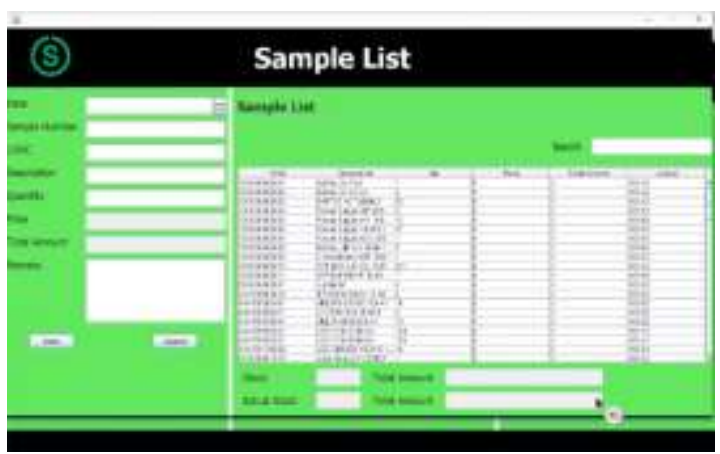

Gambar 13. Tampilan Layar Outgoing Sample
Pada menu sample, user dapat menambahkan, menghapus, mengubah, dan mencari data. Layar ini berfungsi untuk melihat dan menginformasikan mengenai barang keluar yang dipergunakan untuk keperluan sample.

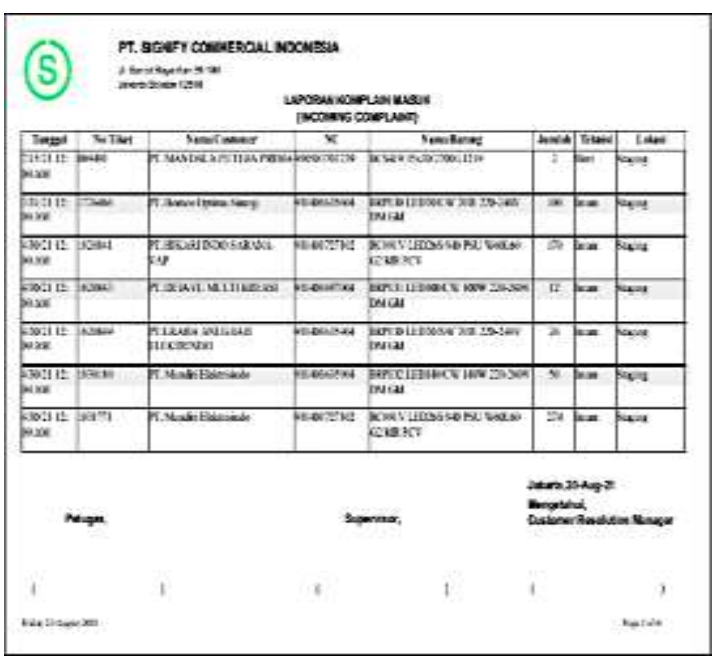

Gambar 14. Tampilan Layar Laporan Data Incoming Complaint

Pada laporan data incoming, user dapat mencetak laporan berdasarkan periode tanggal kedatangan barang. Laporan ini berfungsi untuk melaporkan kedatangan barang complaint berdasarkan periode tertentu.

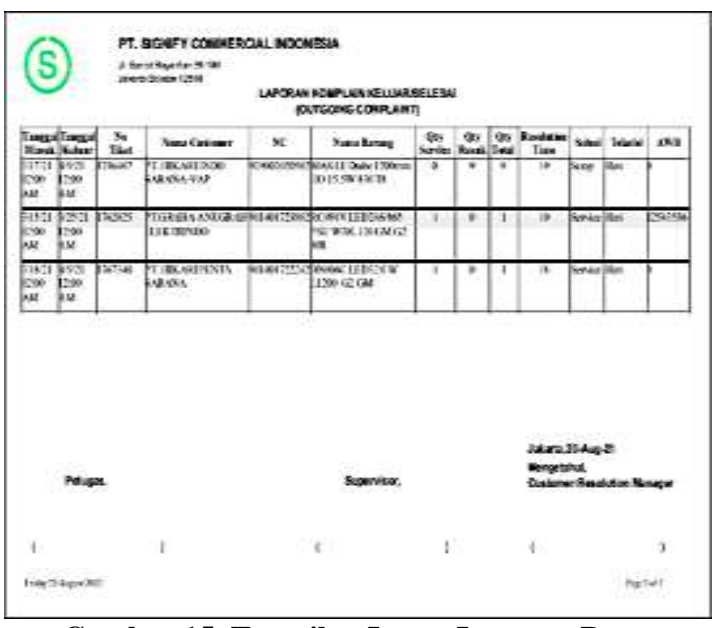

Gambar 15. Tampilan Layar Laporan Data Outgoing Complaint

Pada laporan data outgoing, user dapat mencetak laporan berdasarkan periode tanggal pengeluaran barang. Laporan ini berfungsi untuk melaporkan pengiriman barang complaint berdasarkan periode tertentu. 


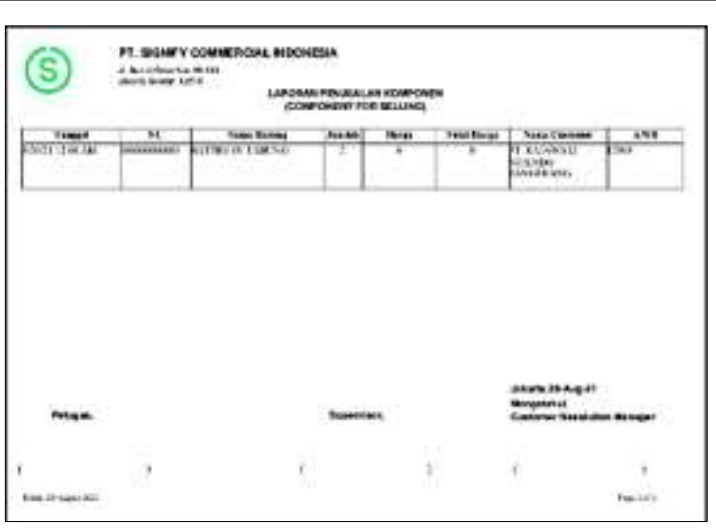

Gambar 16. Tampilan Layar Laporan Data Component For Selling

Pada laporan data component for selling, user dapat mencetak laporan berdasarkan periode tanggal pengeluaran barang. Laporan ini berfungsi untuk melaporkan penjualan komponen berdasarkan periode tertentu.

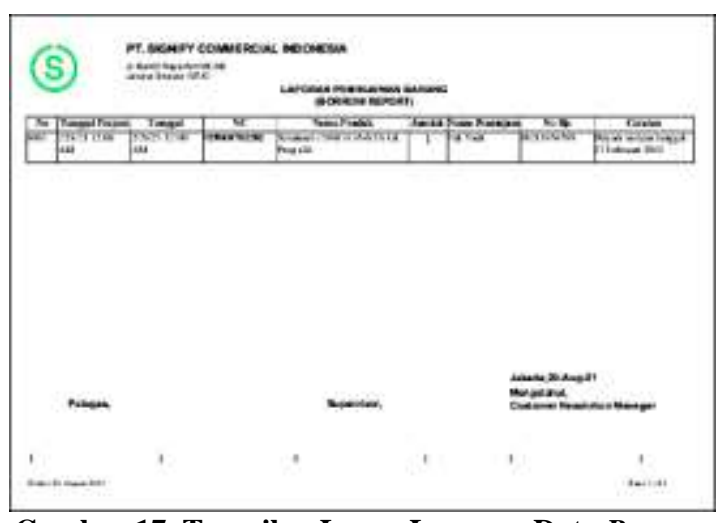

Gambar 17. Tampilan Layar Laporan Data Borrow

Pada laporan data borrow, user dapat mencetak laporan berdasarkan periode tanggal pengeluaran barang. Laporan ini berfungsi untuk melaporkan peminjaman barang berdasarkan periode tertentu.

\section{SIMPULAN DAN SARAN}

Sistem informasi manajemen aktivitas workshop di PT. Signify Commercial Indonesia memudahkan dalam pengelolaan data kedatangan barang (incoming) dan pengeluaran barang (outgoing). Sehingga karyawan dapat memperoleh informasi pendataan dengan baik, cepat dan effisien. Lama pekerjaan sebelum adanya sistem informasi adalah 44 hari menurun menjadi 20 hari kerja dengan stok yang tertata rapi. Hal tersebut menyebabkan pelanggan merasa senang dengan pelayanan yang diberikan. Terbukti setelah sistem berjalan nilai Net Promoter Score (NPS) PT. Signify Commercial Indonesia untuk B2C menjadi terbaik di Worldwide dan $\mathrm{B} 2 \mathrm{~B}$ terbaik kedua di Worldwide.

User Interface masih jauh dari sempurna maka disarankan dikemudian hari tampilan sistem ini dapat ditambahkan gambar/icon tertentu agar lebih menarik lagi. Selain itu pada sistem penyimpanan saat ini masih offline sehingga terjadi keterbatasan pengguna dan waktu penggunaanya disarankan pula dikemudian hari penyimpanan data dapat dilakukan secara online sehingga mempermudah penggunaan.

\section{DAFTAR PUSTAKA}

Amelia, \& Devitra, J. (2018). Analisis dan Perancangan Sistem Informasi Manajemen Persediaan Barang pada Advan Service Center Jambi. Jurnal Manajemen Sistem Informasi, 3(1).

Deni Rohnadi. (2019). Perancangan Sistem Informasi Menejemen Bengkel Di Gama Auto Service. Universitas Islam Indonesia.

Dwi Pratiwi, A. (2020). Perancangan Aplikasi Inventory Barang pada PT Kartika Graha Indonesia Berbasis Java Netbeans. Jurnal Riset Dan Aplikasi Mahasiswa Informatika (JRAMI), 1(03). https://doi.org/10.30998/jrami.v1i03.35 7

Hidayat, A. (2017). Metode Penelitian: Pengertian, Tujuan, Jenis - Uji Statistik. In Www.Statistikian.Com.

Ibeng. (2018). Pengertian Entity Relationship Diagram (ERD). In Www.Pendidikanku.Org: Vol. xii (Issue 33).

Mulyani, P. D. S. (2014). Pengertian Erd. In Marlinda (Vol. 2, Issue 2).

Saifuddin, A. (2010). Metode Penelitia. Metode Penelitian.

Widjoyo, S. (2014). Pengaruh Kualitas Layanan dan Kualitas Produk Terhadap Kepuasan Pelanggan dan Loyalitas Konsumen Restoran Happy Garden Surabaya. Jurnal Manajemen Pemasaran, 2(1).

Ysh, S. (2012). Pengembangan Sistem Pembelajaran. Akprind.

Zeithaml, V.A., Bitner, M.J., Gremler, D. D. (2009). Service marketing (5th ed.). The McGraw-Hill Companies, Inc. 